\title{
The effect of sea-ice loss on beluga whales (Delphinapterus leucas) in West Greenland
}

\author{
M.P. Heide-Jørgensen, ${ }^{1}$ K.L. Laidre, ${ }^{1,3}$ D. Borchers, ${ }^{2}$ T.A. Marques, ${ }^{2}$ H. Stern ${ }^{3}$ \& M. Simon ${ }^{1}$ \\ 1 Greenland Institute of Natural Resources, Box 570, DK-3900 Nuuk, Greenland \\ 2 Research Unit for Wildlife Population Assessment, Centre for Research into Ecological and Environmental Modelling, University of St. Andrews, \\ St. Andrews, Fife KY16 9LZ, UK \\ 3 Polar Science Center, Applied Physics Laboratory, University of Washington, Box 355640, Seattle, WA 98105, USA
}

\section{Keywords}

Beluga; climate change; line transect; sea ice; West Greenland.

\section{Correspondance \\ Mads Peter Heide-Jørgensen, Greenland Institute of Natural Resources, Box 570, DK-3900 Nuuk, Greenland. E-mail: mhj@ghsdk.dk}

doi:10.1111/j.1751-8369.2009.00142.x

\begin{abstract}
An aerial survey was conducted to estimate the abundance of belugas (Delphinapterus leucas) on their wintering ground in West Greenland in March-April 2006 and 2008. The survey was conducted as a double platform aerial line transect survey, and sampled approximately $17 \%$ of the total survey area of ca. $125000 \mathrm{~km}^{2}$. The abundance of belugas was 10595 (95\% confidence interval 4904-24 650). The largest abundance was found at the northern part of Store Hellefiske Bank, at the eastern edge of the Baffin Bay pack ice, a pattern similar to that found in eight systematic surveys conducted since 1981. A clear relationship between decreasing sea-ice cover and increasing offshore distance of beluga sightings was established from all previous surveys, suggesting that belugas expand their distribution westward as new areas on the banks of West Greenland open up earlier in spring with reduced sea-ice coverage or early annual ice recession. This is in contrast to the relatively confined distribution of belugas near the coast in limited open areas in the early 1980s, when sea-ice cover was greater. However, the effects of the changes in coastal availability of belugas can also be observed with the correlation between catches from the local Inuit hunt and sea-ice cover, where the catches increased significantly with increasing sea-ice coverage during the period 1954-2006. These results, based on nearly 30 years of dedicated survey effort, are among the first available evidence showing a shift in distribution of an Arctic cetacean in response to changes in sea-ice coverage.
\end{abstract}

The beluga or white whale (Delphinapterus leucas) is a medium-sized odontocete whale that lives year-round in Arctic waters. A large population that summers in the eastern Canadian High Arctic migrates eastward in fall, and overwinters either in the North Water Polynya or in the loose pack ice along West Greenland (HeideJørgensen et al. 2003). Belugas arrive in the northern part of West Greenland in early October and move south along the coast, arriving in Disko Bay in December. They remain scattered on the shallow banks along the West Greenland coast during winter, where they feed and benefit from the rich marine production in the area. The northward spring migration begins sometime in April or May. Belugas leave the areas south of Disko Island and move north in the coastal open water along Uummannaq and Upernavik. They are believed to cross Baffin Bay somewhere at the latitude of Upernavik (about $73^{\circ} \mathrm{N}$ ), and they arrive at the ice edge in Lancaster Sound in Canada in May and June.

Beluga whales are one of the three cetacean species that occupy Arctic waters essentially year-round. However, little is known about the effects of climate change on this species, as there are few data sets in which a single population has been systematically monitored over a sufficiently long enough time period to detect changes in abundance, distribution or behaviour, and correlate changes with changes in the environment. The beluga is believed to be a relatively flexible species in that it preys upon a large number of different species and can occupy a wide variety of different habitat types, ranging 
from High Arctic ice-covered waters to sub-Arctic estuaries. Because this whale is a relative generalist and is not assumed to be highly vulnerable to climate change (Laidre et al. 2008), it has been suggested that belugas may be able to occupy new areas and exploit new ecosystems as sea-ice loss opens new regions within their range.

The winter occurrence of belugas in West Greenland has been used to index the population trends in the stock hunted from villages along the coast. The area in West Greenland used by belugas during winter is typically covered with pack ice from January to May. Seasonal sea-ice cover in Baffin Bay has essentially confined this wintering population to a relatively defined region, facilitating a surveying effort that covered about $50000 \mathrm{~km}^{2}$ between 1981 and 1999. The abundance of belugas was surveyed eight times between 1981 and 1999 to provide an index of the population size on the banks off West Greenland (Heide-Jørgensen et al. 1993; HeideJørgensen \& Reeves 1996; Heide-Jørgensen \& Acquarone 2002). In order to address important questions about the effect of habitat changes on cetacean populations it is necessary to have long time series. The aerial surveys conducted off West Greenland since 1981 constitute the only time series of winter habitat use by Arctic cetaceans that extends sufficiently far back in time to include a period when sea ice was not declining in the Arctic. Detailed information on catches of belugas in West Greenland covering the period back to 1954 is available.

It is well known that the effects and speed of climate change are amplified in the Arctic, and that sea ice, because of the ice-albedo feedback, is an important factor in the Arctic amplification of global warming (e.g., Serreze $\delta$ Francis 2006). The West Greenland area is a particularly sensitive climate area in the Arctic because of the competing effects of the advection of warm, saline Atlantic water to the West Greenland banks, and the simultaneous outflow through Davis Strait of cold, low-saline water of polar origin. During the period 1952-2001 the extent of sea ice in West Greenland increased slightly by $2.8 \%$ per decade (Stern \& Heide-Jørgensen 2003), but after 2001 a dramatic decline in sea ice has been observed along West Greenland (Comiso 2006; Greenland Institute of Natural Resources unpubl. data). It is therefore important to not only obtain an updated estimate of beluga abundance, but also to examine the impacts of changes in sea ice on measures of beluga abundance and distribution. This study reports on the results from aerial surveys of the beluga wintering grounds in West Greenland conducted in March and April 2006, and in April 2008, together with an examination of changes in beluga distribution with respect to changes in sea-ice cover during the past 30 years.

\section{Methods}

\section{Field methods}

A visual aerial line-transect survey was conducted in West Greenland between 21 March and 19 April 2006. The survey had two independent observation platforms on each side of the survey plane (DeHavilland Twin Otter with four bubble windows), with a target altitude of $213 \mathrm{~m}$ a.s.l. and speed of $168 \mathrm{~km} \mathrm{~h}^{-1}$. Data on sightings (species and numbers), inclinometer readings of declination angles to sightings and sighting conditions (sea state and visibility) were continuously recorded on four tape recorders, together with time-stamp signals on position from a Garmin 100 GPS device (Garmin International, Olathe, KS, USA). Following the design and stratification used in previous surveys (see Heide-Jørgensen \& Reeves 1996) the survey covered 14 strata with east-west transects systematically placed from south to north, beginning at Maniitsoq $\left(65^{\circ} 30^{\prime} \mathrm{N}\right)$, and reaching Northern Upernavik $\left(74^{\circ} \mathrm{N}\right)$ in West Greenland. Additional transects sampled Disko Bay, Vaigat and Uummannaq (Fig. 1). The survey was abandoned if sea states increased to more than 3 or if horizontal visibility was reduced to less than $1 \mathrm{~km}$.

In April 2008 a supplementary survey systematically covered the area east of $56^{\circ} \mathrm{W}$, and between 67 and $70^{\circ} \mathrm{N}$. The survey used the same aircraft, four observers and same survey procedures as in the 2006 survey, but is not used for abundance estimation. Sightings of belugas were recorded on an SDVR-ms combined video, still image, GPS device and four audio channel recording system (Red Hen Systems, Fort Collins, CO, USA).

\section{Information on sea-ice conditions}

Data on sea-ice conditions in Baffin Bay were derived from monthly gridded sea-ice concentrations, measured by passive microwave sensors from the scanning multichannel microwave radiometer (SMMR, 1978-1987) and the special sensor microwave imager (SSMI, on various satellites since 1987). This data set was augmented by the SSMI from the F13 satellite (from May 1995 to the present). Both data sets are derived using the bootstrap algorithm for sea-ice concentration (Comiso 1995), and are available from the National Snow and Ice Data Center. Sea-ice data from March 2008 were obtained from the SSMI F1 5 Near Real Time daily products (NASA Team algorithm).

Each sea-ice concentration grid for the Northern Hemisphere is $304 \times 448$ pixels, and is mapped to a polar stereographic projection (true at $70^{\circ} \mathrm{N}$ ) with a nominal pixel size of $25 \times 25 \mathrm{~km}$. The "medium area" (boundaries: $65-70^{\circ} \mathrm{N}$, and from the west coast of Greenland to $58^{\circ} \mathrm{W}$ ) along West Greenland defined in Stern \& Heide- 


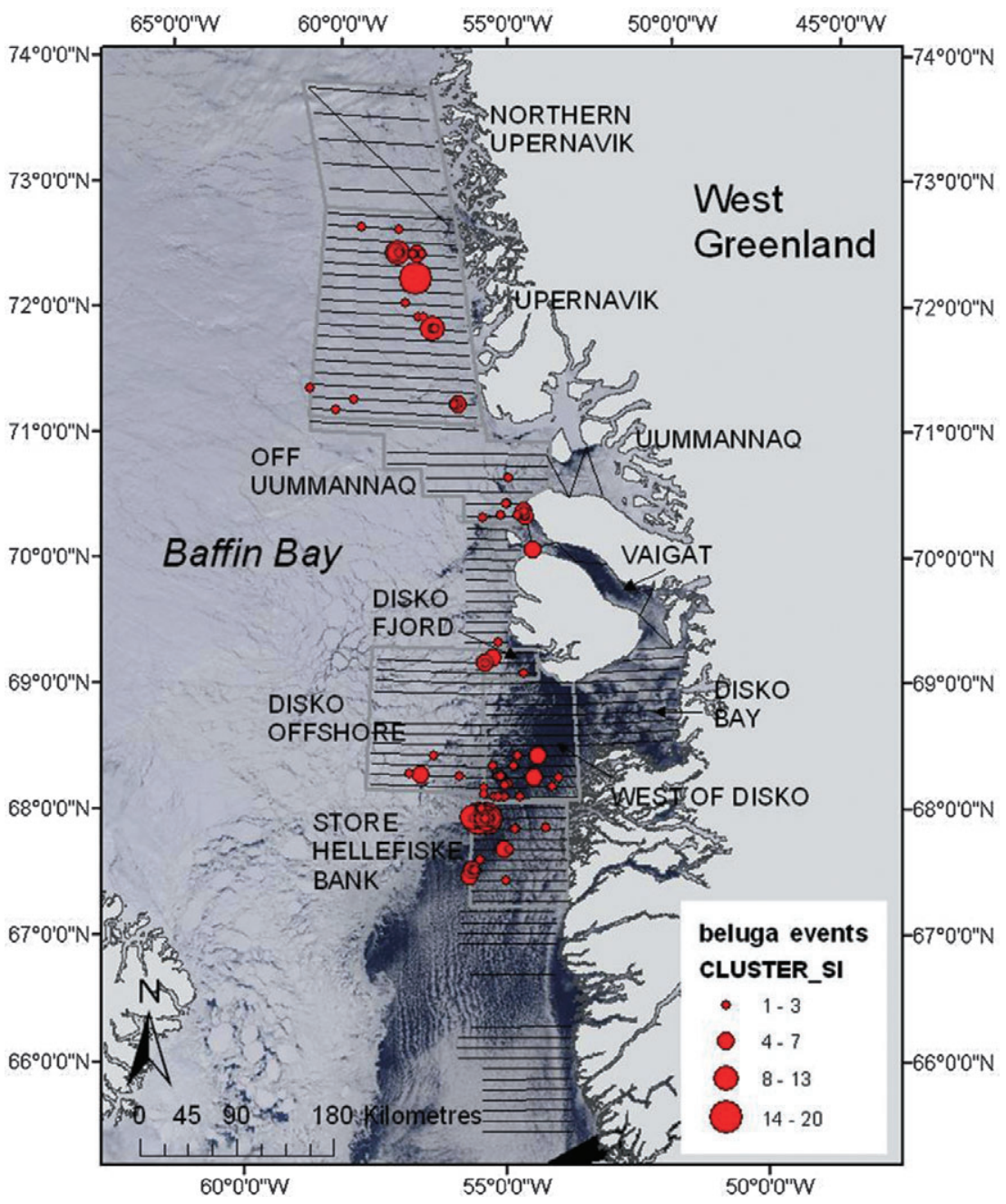

Fig. 1 Transect lines and distribution of sightings in the survey of belugas in West Greenland, March-April 2006. Sea ice is mapped from a MODIS image from 18 April 2006.
Jørgensen (2003) was used for the estimation of the annual sea-ice extension in the beluga habitat in West Greenland. The sea-ice concentration in March, typically the month with the largest concentration, was used to compute an area-weighted average over all pixels to get the mean winter sea-ice concentration. Thus, the monthly estimates of ice concentration involved spatial and temporal averaging.

\section{Sighting data}

Declination angles $(\theta)$ were converted to perpendicular distances $(r)$ using the formula:

$$
r^{2}=213 / \sin \left([\theta * \pi / 180]^{2}-213^{2}\right) .
$$

A total of 119 beluga sightings were recorded. Five of those did not have a recorded declination angle, and two lacked information on cluster size. These were excluded from the analysis to avoid bias from sightings with missing information, resulting in 112 sightings to be used in further analysis. Beaufort sea state 0 was assigned to 13 sightings without an associated Beaufort value, as the general sea-state condition was known during the trackline upon which they were obtained.

\section{Detection function model selection}

Detection probability was estimated using the "point independence" method with independent observer configuration (Laake \& Borchers 2004; Borchers et al. 2006), implemented in DisTANCE 5.0 (Thomas et al. 2006). This method involved estimating a multiple covariate distance sampling model (mcds model) for combined platform detections assuming certain detection at distance zero, and a mark-recapture distance sampling model (mrds model) for each of the independent observers using a logistic detection function model. The intercept of the mrds model was used to estimate detection probability at 
distance zero, whereas the mcds model was used to estimate detection function shape (see Laake $\&$ Borchers 2004 and Borchers et al. 2006 for further details). Models were chosen on the basis of Akaike's information criterion (AIC). Forward selection was used to choose between models based on AIC values. First, half-normal and hazard-rate key functions were tested with no covariates.

A regression of $\log$ of pod size on $\log$ of detection function was used to estimate an unbiased mean pod size for each stratum $(\hat{E}[s])$. The estimates for pod abundance and density by stratum were multiplied by the mean pod size by stratum to obtain estimates of individual abundance and density by stratum. Total pod abundance and density estimates were also multiplied by the total mean pod size to obtain total individual abundance and density estimates.

Pod density and abundance were estimated as follows, corrected for availability bias following Laake et al. (1997) and Pollock et al (2006):

$$
\hat{N}_{p o d}=\sum_{i=1}^{n} \frac{1}{\hat{p}_{i} \hat{a}(0)}
$$

and

$$
\hat{D}_{p o d}=\frac{\hat{N}}{A}
$$

where $A$ is the total area, $n$ is the number of detections, $\hat{p}_{i}$ is the estimated probability of detecting pod $i$ and $\hat{a}(0)$ is the estimated proportion of time animals are available for detection. Time at surface was calculated as the mean of the correction factors from two previous surveys, to correct for availability bias (Heide-Jørgensen \& Acquarone 2002; Innes et al. 2002). To include the population variance on the surfacing time, an estimate of the coefficient of variation was set to 0.09 , or slightly less than the coefficient of variation $(\mathrm{cv}$, standard error in proportion to the mean) reported for a small sample $(n=4)$ of narwhals (Monodon monoceros) ( $\mathrm{cV}=0.13)$. This was equal to an instantaneous correction factor $\hat{a}(0)=0.43(\mathrm{cv}=0.09)$.

Assuming independence between components, the $\mathrm{cV}$ of the abundance and density estimates were estimated as follows:

$$
c v(\hat{N})=\sqrt{c v_{\hat{N} p o d}^{2}+c v_{\hat{E}(s)}^{2}+c v_{\hat{a}(0)}^{2}} .
$$

The 95 and $90 \%$ confidence intervals (CIs) were calculated following the derivation of Burnham et al. (1987, in Buckland et al. 2001: 77).

\section{Interannual comparison of beluga locations}

In the region between 67 and $70^{\circ} \mathrm{N}$ beluga abundance has been surveyed systematically with the same east-west transect lines in 1981, 1982, 1990, 1991, 1993, 1994, 1998 and 1999, allowing for comparison of the distribution of whales in this area (Heide-Jørgensen et al. 1993; Heide-Jørgensen \& Reeves 1996; Heide-Jørgensen \& Acquarone 2002). Surveys after 1990 relied on GPS, the surveys in 1981 and 1982 used the GNS 500 global navigational system device (Garmin International), and the survey in 1990 used a 3000 Omega navigational system device (Litton Industries, acquired in 2001 by Northrup Grumman, Los Angeles, CA, USA). Surveys in 1981 and 1982 of Baffin Bay and Davis Strait found no belugas west of $56^{\circ} \mathrm{W}$ in late March (Heide-Jørgensen et al. 1993), so later surveys were restricted to $56^{\circ} \mathrm{W}$. The comparison between years with surveys was constrained to a subset of longitudes that were surveyed in all years, which extended to $56^{\circ} \mathrm{W}$, and were located between 67 and $70^{\circ} \mathrm{N}$.

The mean longitude of beluga sightings (in decimal degrees) in each survey year within the restricted area was calculated. In each year the mean longitude was examined with respect to sea-ice concentration in the "medium area" (see above), which has been shown to be correlated with the sea-ice conditions in the surveyed area (see Heide-Jørgensen \& Laidre 2004).

\section{Results}

\section{Distribution of belugas}

The surveys were conducted between 21 March and 19 April 2006, and between 3 and 12 April 2008, beginning in the southern strata (Figs. 1, 2). Because of inclement weather conditions most work was completed between 7 and 24 April 2006 (Table 1).

In 2006 belugas were primarily found in coastal areas along West Greenland and over shallow water $(<200 \mathrm{~m}$ deep). No belugas were found south of $67^{\circ} \mathrm{N}$ or north of $73^{\circ} \mathrm{N}$, and none were detected in Disko Bay and in Uummannaq. Belugas were seen in the highest densities at the northern edge of Store Hellefiske Bank, just west of Disko Island, in the northern opening of Vaigat and off Upernavik. At the northern edge of Store Hellefiske Bank, belugas were observed at the western end of the transect indicating that whales may have been present even further west in this area. Few whales were seen in open water, and they seemed to be closely associated with the eastern margin of the pack ice that covers most of Baffin Bay and Davis Strait (Fig. 1). In 2008 the belugas were more restricted in their offshore distribution because of the wider distribution of pack ice, and most sightings were made in open water close to the coast (Fig. 2). 


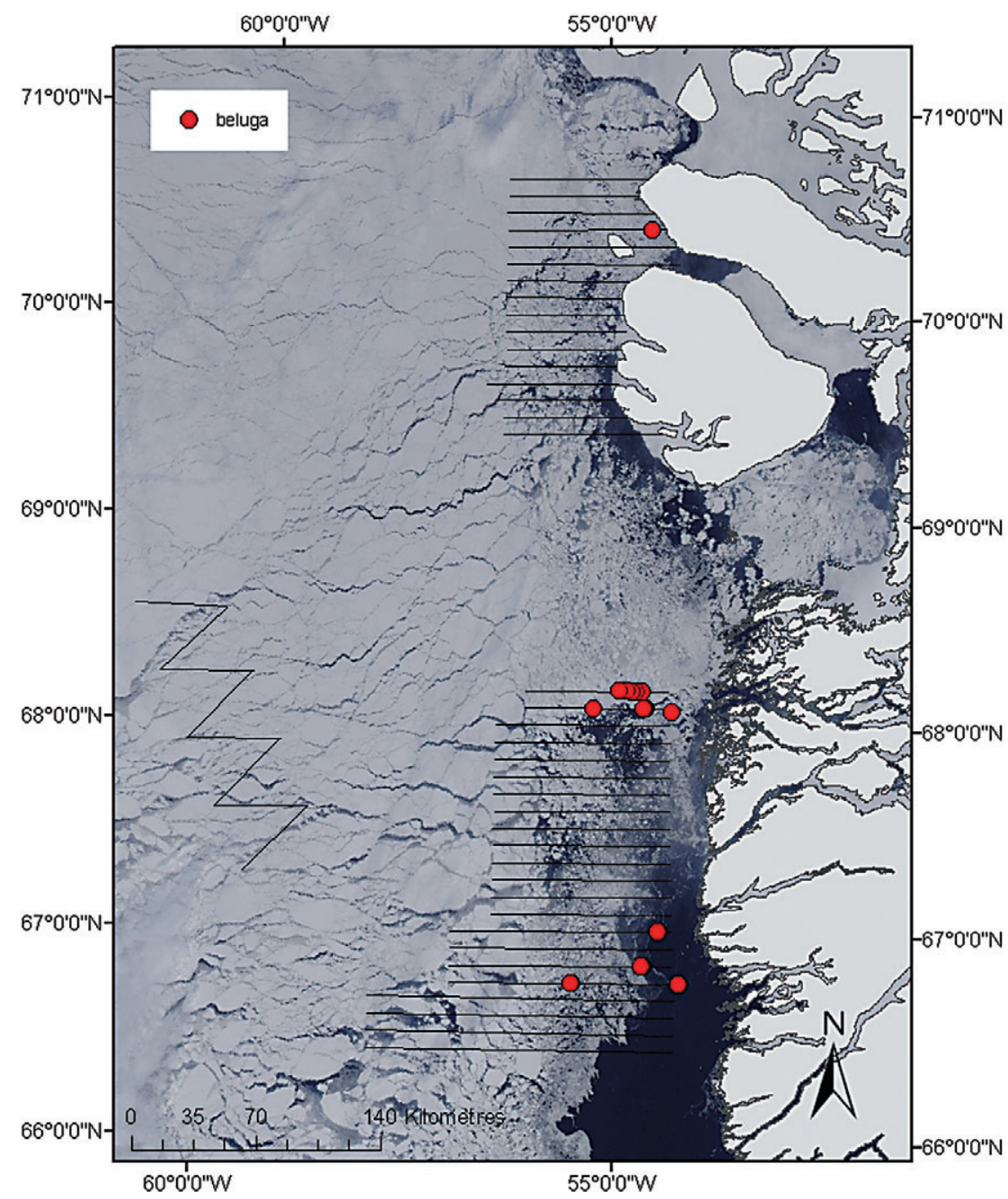

Fig. 2 Transect lines and distribution of sightings in the survey of belugas in West Greenland, April 2008. Sea ice is mapped from a MODIS image from 3 April 2008.

\section{Abundance of belugas in 2006}

Almost half of the detections in 2006 were of single whales, with only about $13 \%$ of the pod sizes being larger than five whales. The overall estimate of mean pod size was $3.0(\mathrm{cv}=0.11)$. The unbiased or expected estimates of mean pod sizes varied between one and four whales, with an overall mean across all strata of 2.9 whales per $\operatorname{pod}(\mathrm{cv}=0.20$; Table 1$)$.

A hazard-rate key function with Beaufort sea state and cluster size as covariates was selected based on its lower AIC value, and estimates of abundance and density were obtained from this model with a right truncation at $1000 \mathrm{~m}$ (Fig. 3).

The largest abundance of belugas was found in stratum $3(5891, \mathrm{cv}=0.78)$, which covered the northern portion of Store Hellefiske Bank. The second largest abundance was found in stratum 13 in Upernavik $(3256, \mathrm{cv}=0.44)$. The total abundance at the surface, and corrected for perception bias, summed across all strata was 5298 belugas (95\% CI 2407-11 676). The total abundance corrected for both perception and availability bias was 11773 belugas ( $\mathrm{cv}=0.43$; Table 1$)$. The correction for availability bias assumes that the sighting process was instantaneous, which is generally not true as some whales are sighted ahead of the plane. To address this point we used a correction model developed for narwhals based on McLaren's formula (McLaren 1961), in which the whales were visible for an average of $4 \mathrm{~s}$ from the airplane, with a dive cycle of $36 \mathrm{~s}$ at the surface and $167 \mathrm{~s}$ submerged below $2 \mathrm{~m}$ (Richard et al. in press). This correction model shows that because of the non-instantaneous sighting process, the instantaneous availability correction has a positive bias of roughly $10 \%$. Adjusting for this factor results in a revised abundance estimate of 10595 (95\% CI 490424650 ) belugas in West Greenland in March-April 2006. 


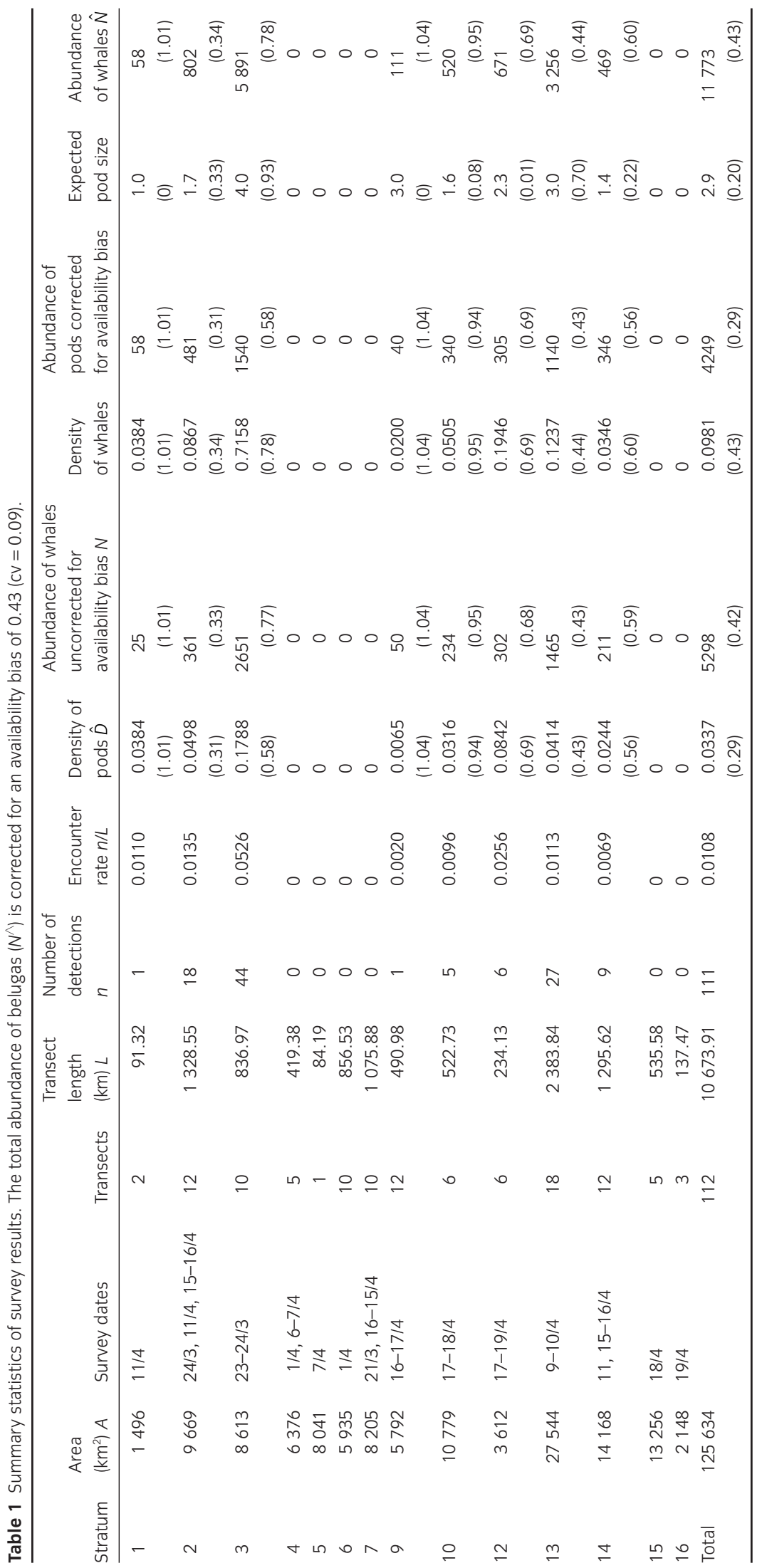




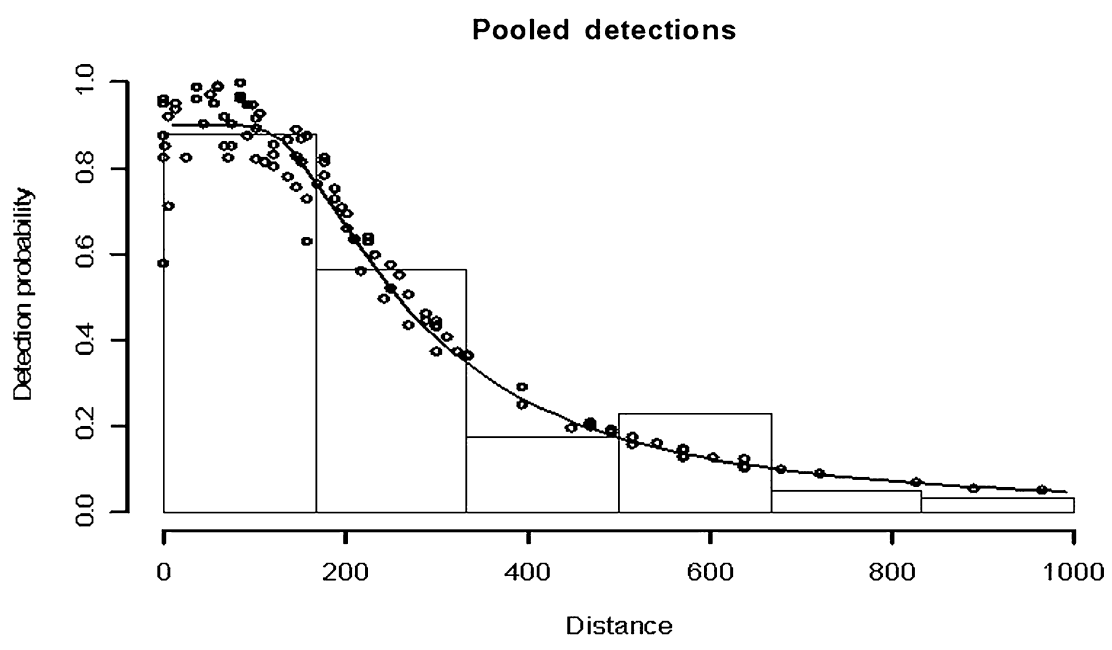

Fig. 3 Detection probability of the pooled detections from both rear and front observers. The distances of sightings were truncated at $1000 \mathrm{~m}$.

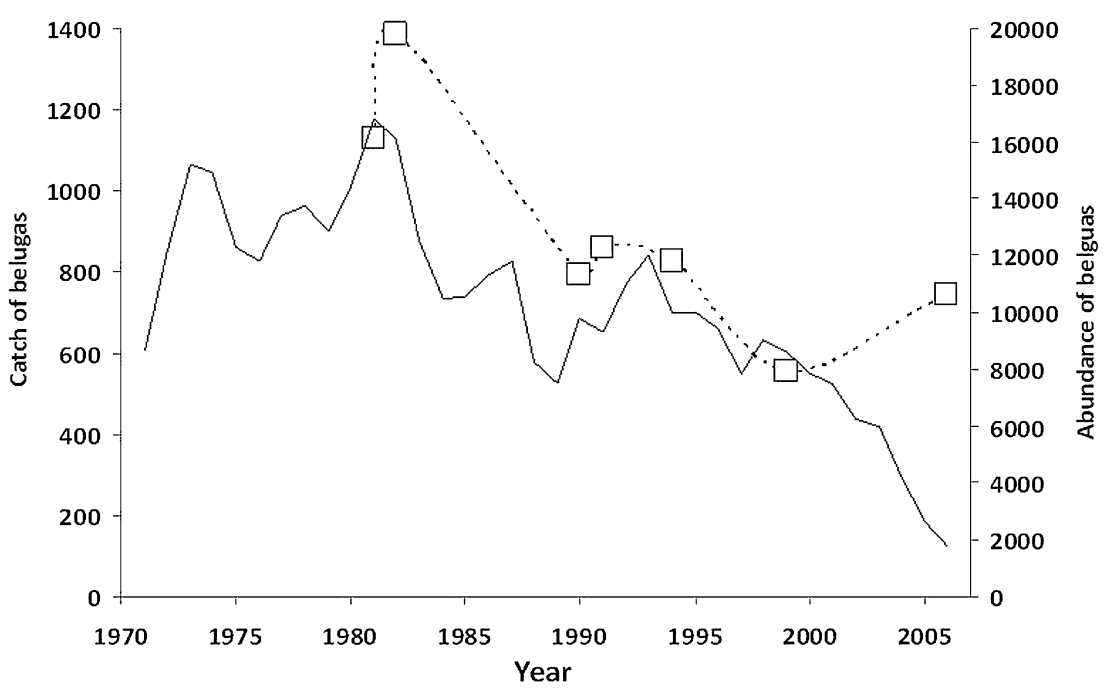

Fig. 4 Trends in catches and abundance of belugas in West Greenland from 1970 to 2006. Catches are shown with a solid line as a twoyear sliding average, and abundance is shown as a dotted line, with squares indicating years where abundance estimates can be derived. The catch data are from Heide-Jørgensen \& Rosing-Asvid (2002; "medium option" and no ice entrapments) and Greenland Institute of Natural Resources (unpubl. data). Abundance estimates are from Heide-Jørgensen \& Acquarone (2002) and this study, and were derived from a population model presented in Alvarez-Flores \& Heide-Jørgensen (2004). A quota was established to regulate the catch in 2006.
Previous surveys have used an index for backward compatibility with the 1981 and 1982 strip census surveys. This assumes constant sightability within a strip width of $700 \mathrm{~m}$ on either side of the aircraft, and a simple sum of sightings rather than a pod size extrapolation of sightings. Within the two strata (west of Disko Bay and Store Hellefiske Bank) covered in previous surveys, the index value was 1146 belugas ( $\mathrm{cV}=0.25,95 \%$ CI 708-1855).

\section{Trends in abundance}

The abundance estimate of $10595(\mathrm{cV}=0.43)$ belugas from 2006 represents a modest increase in abundance since 1999, when the last abundance estimate of 7941 $(\mathrm{cv}=0.32)$ belugas was derived. The two estimates are not significantly different. Similarly, the index estimate from 2006 was slightly larger, but not significantly larger, than the estimates from 1998 (929, 95\% CI 563-1533) and 1999 (735, 95\% CI 436-1239) (Heide-Jørgensen \& Acquarone 2002). When comparing the population trajectory to the catch series for the period 1970-2006 it appears that the recent abundance estimates represent a slight recovery from the population decline observed over the past 25 years (Fig. 4).

\section{Changes in sea ice in the beluga wintering area}

During winters in the period 1979-2006 the pack-ice edge $(>85 \%$ sea-ice concentration) reached the coast of West Greenland at approximately $66.9^{\circ} \mathrm{N}$ (HeideJørgensen et al. 2007). At the time of its maximum extent the winter sea ice in Baffin Bay and Davis Strait usually leaves a stretch of open water along Greenland's west coast, extending from south-west Greenland to Disko Bay, with dense pack ice $(>85 \%)$ prevailing north of $66.9^{\circ} \mathrm{N}$. However, since 2002 the eastern part of Baffin 
Fig. 5 Time trends of sea-ice coverage in West Greenland and the average longitude of beluga sightings (between 67 and $70^{\circ} \mathrm{N}$ and east of $56^{\circ} \mathrm{W}$ ) during midwinter surveys between 1981 and $2008\left(r^{2}=0.79\right)$. Sea-ice data are from the "medium area" of West Greenland in Stern \& Heide-Jørgensen (2003), and were updated through 2008.
Fig. 6 The correlation between catches of belugas and midwinter sea-ice extent in West Greenland $\left(r^{2}=0.28\right)$. The slope of the regression is significant (ANOVA, $P<0.0001$ ). Sea-ice data are from the "medium area" of West Greenland in Stern \& Heide-Jørgensen (2003), and were updated through 2006. Catch data are from the medium option without ice entrapments from Heide-Jørgensen \& RosingAsvid (2002), and were updated through 2006.
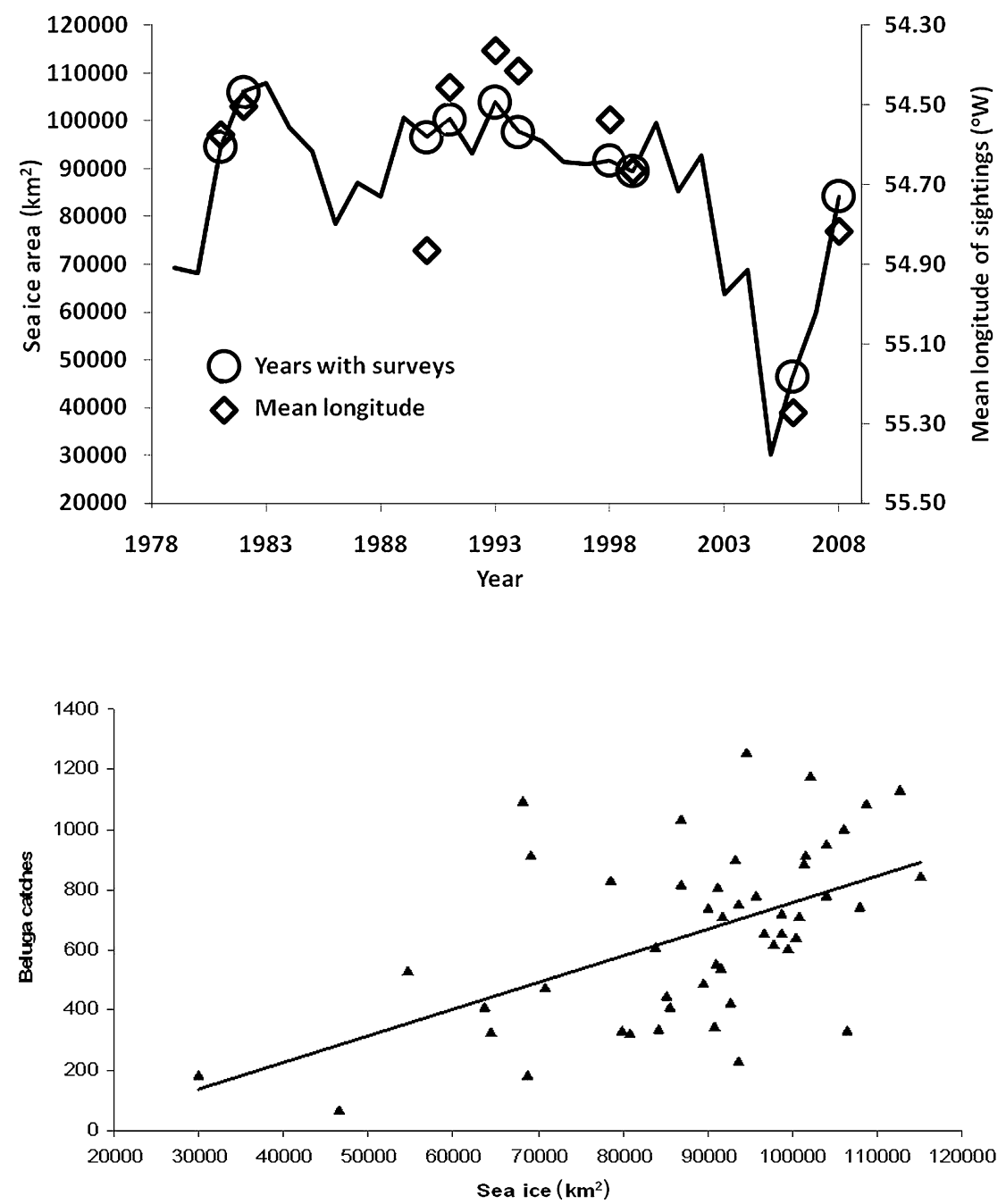

Bay and Davis Strait has experienced a dramatic decline in the extent of winter pack ice. During the survey in 2006 the extent $\left(46560 \mathrm{~km}^{2}\right)$ was less than $50 \%$ of the average sea-ice coverage during the years with surveys between 1981 and $1999\left(94895 \mathrm{~km}^{2}\right.$ ). In 2007 and 2008 the extent of sea ice in Baffin Bay partly recovered to similar levels observed before 2002 (Fig. 5).

\section{Trends in the geographic position of the wintering concentration of belugas}

The mean longitude of the beluga sightings has no trend between 1981 and 1999, but in 2006 it moves further west, and it almost recovers the original position in 2008 (Fig. 5). The change in mean longitudinal position of the whales was significantly correlated with the extent of sea ice (ANOVA, $P=0.0006$ ), so it appears that the effect was mainly driven by the reduced and westward retraction of sea ice that was encountered in 2006. The survey in 2008 encountered sea-ice extension similar to pre-2002 levels, and the belugas were again concentrated in the more eastern area, where they were previously found (Fig. 2).

\section{Trends in catches of belugas in relation to sea ice in 1954-2006}

Belugas are hunted coastally along West Greenland, and the catches during the period 1954-2006 are positively correlated $\left(r^{2}=0.28\right)$ with the annual midwinter extension of sea ice. The largest catches are observed in years with heavy ice coverage along the West Greenland coast (Fig. 6). A special form of beluga hunting occurs when the whales are entrapped in sea ice (Sassat), but this type of event has not been observed in years with less than $70000 \mathrm{~km}^{2}$ of midwinter sea-ice extent along West Greenland during the period 1951-2006. 


\section{Discussion}

\section{Changes in distribution and the effect of sea ice}

The distribution of beluga whales based on sightings from the survey in 2006 shares three characteristics with previous surveys. First, the stratum on Store Hellefiske Bank was clearly the most important area for belugas in West Greenland. In 2006, approximately $50 \%$ of the total abundance was found in this area, compared with the average between 1981 and 1999 of $41 \%$ (range 15-51\%). Second, no belugas were found inside Disko Bay, agreeing well with the distribution from past surveys. Third, belugas found in the northern part of Vaigat confirm that this is an important wintering area, agreeing well with past survey results.

There are important differences between the distribution of belugas in the 2006 survey and previous years. The area south of Store Hellefiske Bank had no sightings of belugas in 2006, and contributed nothing to the overall abundance estimate. In contrast, all eight surveys conducted in the period 1981 to 1999 had sightings in this area (Heide-Jørgensen et al. 1993; Heide-Jørgensen \& Reeves 1996; Heide-Jørgensen \& Acquarone 2002), suggesting that the distribution of belugas in West Greenland has shifted northward. The average contribution to the total abundance from this area in the previous surveys was $38 \%$ (range $14-67 \%$ ). In contrast, about $43 \%$ of the total abundance estimate in 2006 came from areas located north of Disko Island. The surveys in 1982 and 1990 attempted to survey parts of these northern areas; however, searches north of Disko Bay were abandoned because of a lack of sightings north of Vaigat, and because of heavy sea-ice coverage.

The decline in sea-ice coverage of the eastern part of Baffin Bay between 2002 and 2006 probably provided belugas access to a larger area, and allowed the wintering stock to be more widely dispersed over the banks of West Greenland. In the surveys before 2006, extensive sea-ice coverage only provided open water for the belugas along the coast south of Disko Island and in the polynya in Vaigat, and restricted both the areas belugas could use as well as the areas that were considered important to survey for belugas. In 2008 it could be observed that the westward transition of the belugas was reversible with the recovery of sea-ice extension in 2007 and 2008.

The changes in sea-ice conditions in West Greenland have been dramatic, especially after 2002, when about half the midwinter ice disappeared compared with the ice coverage between 1981 and 2002. This change in springtime physical conditions happened directly over the wintering ground for belugas in Baffin Bay, and has evidently affected the distribution of the whales. The formation of sea ice forces the whales closer to the coast in more restricted areas, where they can be targeted by local Inuit hunters and where they are picked up by the surveys. With the loss and westward retraction of sea ice, belugas have followed the ice over deeper water towards the edge of the banks. Local observations have noted the absence of whales in coastal areas during 2002-06, and it is also evident that there is a reduced availability for the coastal hunt of belugas. The opening of sea ice along the coast has also allowed a large number of belugas to travel north in spring towards Upernavik, to an area inaccessible to hunters, where they are not known to be found early in spring.

\section{Trends and abundance estimates}

The declining abundance of belugas in West Greenland has been observed from 1981 to 1999 (Heide-Jørgensen $\&$ Acquarone 2002). The population in 2000 was estimated to number only $22 \%$ of its size in 1954, and the decline was attributed to overharvesting (Alvarez-Flores \& Heide-Jørgensen 2004). The period from 1979 to 2001 , when the decline was detected, had a slightly increasing sea-ice concentration in eastern Baffin Bay/West Greenland, of $3.5 \%$ per decade (Stern and Heide-Jørgensen 2003). During this period a smaller area of open water was available for belugas wintering in West Greenland, restricting the whales to the coastal areas captured by the surveys. This was demonstrated in the survey in March 1981, when no belugas were detected in the offshore areas of Baffin Bay (Heide-Jørgensen et al. 1993). Also, satellite tracking of belugas fitted with transmitters in 2001 showed their fidelity to coastal areas in West Greenland (Heide-Jørgensen et al. 2003). During the period of population decline the ice coverage was relatively constant or slightly increasing. The beluga decline is therefore unlikely to be linked to sea-ice changes. In 2006 the ice conditions had changed dramatically, with the consequence being that the belugas were spread out over a larger area, seeking the edge of the offshore banks. The decline in ice coverage in 2006 also left an area almost twice as large as previous years to be surveyed. Interestingly, in 2008 ice coverage again increased, and the belugas were more coastal in their central distribution than in 2006, although their abundance could not be estimated.

The total abundance corrected for both perception and availability bias was 10595 belugas (95\% CI 5260$26400)$. The latest survey of belugas in West Greenland was conducted in 1998 and 1999, and the similarly fully corrected abundance estimate was 7941 belugas (95\% CI 3650-17 278) (Heide-Jørgensen \& Acquarone 2002). This value is not statistically different from the result from 
the current survey, despite the fully corrected point estimate being higher.

Factors that might have contributed to the recent increase in the abundance of belugas in West Greenland include a decline in catches since the mid-1990s. Catches have been below 500 per year since 1999, and a new quota installed in 2004 limited the catches to 160 whales per year, considerably less than the average catch level off 688 belugas per year in the 1990s. Furthermore, no ice entrapments of belugas have been observed since 1990, which suggests a reduction in large-scale natural mortality events.

\section{Conclusion}

The time series on beluga locations in winter in West Greenland presented here was not collected with the purpose of observing the effects of climate change on beluga habitat selection. Nevertheless, it is one of the few time series of winter occurrence of Arctic whales that goes sufficiently far back in time to assess the situation before the dramatic sea-ice recession. The migratory pattern of the belugas seems to be shaped by the annual cycle in freeze-up and sea-ice retraction over longer time periods.

It is clear that the belugas that winter in West Greenland prefer to stay close to the edge of the pack ice, and that they utilize any loosening in the pack ice to move further north or further west to more offshore areas. It is nevertheless difficult to predict what will happen in the future given that sea-ice coverage increased slightly until 2002, after which time it showed a dramatic decline through 2006, but partially recovered in 2008. So there is currently no monotonic trend on which to base predictions. If the recovery in sea ice continues then the situation will return to "normal", i.e., the situation observed in the1980s. If a decline in sea-ice distribution continues the whales are expected to be more widespread in the offshore areas of Davis Strait-Baffin Bay in the future. Belugas seem to be able to respond well to largescale habitat changes. Global warming and sea-ice declines may pose less of a problem for belugas than to other Arctic marine mammals.

\section{Acknowledgements}

The observers Fernando Ugarte, Karolina Platou Larsen, Arne Geisler and Aili Labansen are gratefully acknowledged for their contribution. Air Greenland and several skilled crews operated the Twin Otter. The survey in 2006 was funded by the Greenland Institute of Natural Resources. The aerial survey in 2008 was funded by the US National Aeronautics and Space Administration, and funding for the Red Hen recording system was obtained from the Vetlessen Foundation. HS acknowledges support from the US National Science Foundation.

\section{References}

Alvarez-Flores C. \& Heide-Jørgensen M.P. 2004. Risk assessment of the beluga (Delphinapterus leucas) harvest in West Greenland. ICES Journal of Marine Science 61, 774-786.

Borchers D.L., Laake J.L., Southwell C. \& Paxton C.G.M. 2006. Accommodating unmodelled heterogeneity in double-observer distance sampling surveys. Biometrics 62, 372-378.

Buckland S.T., Anderson D.R., Burnham K.P., Laake J.L., Borchers D.L. \& Thomas L. 2001. Introduction to distance sampling: estimating abundance of biological populations. New York: Oxford University Press.

Comiso J.C. 1995. SSM/I sea ice concentrations using the bootstrap algorithm. NASA Reference Publication 1380. Greenbelt, MD: Goddard Space Flight Center.

Comiso J. 2006. Abrupt decline in the Arctic winter sea ice cover. Geophysical Research Letters 33, L18594, doi: 10.1029/ 2006GL027341.

Heide-Jørgensen M.P. \& Acquarone M. 2002. Size and trends of the bowhead, beluga and narwhal stocks wintering off West Greenland. Scientific Publications of the North Atlantic Marine Mammal Commission 4, 191-210.

Heide-Jørgensen M.P. \& Laidre K.L. 2004. Declining extent of open water refugia for top predators in Baffin Bay and adjacent waters. Ambio 33, 488-495.

Heide-Jørgensen M.-P., Lassen H., Teilmann J. \& Davis R.A. 1993. An index of the relative abundance of wintering belugas, Delphinapterus leucas, and narwhals, Monodon monoceros, off West Greenland. Canadian Journal of Fisheries and Aquatic Sciences 50, 2323-2335.

Heide-Jørgensen M.P. \& Reeves R.R. 1996. Evidence of a decline in beluga abundance (Delphinapterus leucas) off West Greenland. ICES Journal of Marine Science 53, 61-72.

Heide-Jørgensen M.P., Richard P., Dietz R., Laidre K.L. \& Orr J. 2003. An estimate of the fraction of belugas (Delphinapterus leucas) in the Canadian High Arctic that winter in West Greenland. Polar Biology 23, 318-326.

Heide-Jørgensen M.P. \& Rosing-Asvid A. 2002. Catch statistics for belugas in West Greenland 1862 to 1999. Scientific Publications of the North Atlantic Marine Mammal Commission 4, 127-142.

Heide-Jørgensen M.P., Stern H. \& Laidre K. 2007. Dynamics of the sea ice edge in Davis Strait. Journal of Marine Systems 67, 170-178, doi: 10.1016/j.jmarsys.2006.10.011.

Innes S., Heide-Jørgensen M.P., Laake J., Laidre K.L., Cleator H., Richard P. \& Stewart R.E.A. 2002. Surveys of belugas and narwhals in the Canadian High Arctic in 1996. Scientific Publications of the North Atlantic Marine Mammal Commission 4, 169-190. 
Laake J.L. \& Borchers D.L. 2004. Methods for incomplete detection at distance zero. In S.T. Buckland et al. (eds.): Advanced distance sampling. Pp. 108-189. Oxford: Oxford University Press.

Laake J., Calambokidis J., Osmek S.D. \& Rugh D.J. 1997. Probability of detecting harbour porpoise from aerial surveys: estimating g(0). Journal of Wildlife Management 61, 63-75.

Laidre K.L., Stirling I., Lowry L.F., Wiig Ø., Heide-Jørgensen M.P. \& Ferguson S.H. 2008. Quantifying the sensitivity of Arctic marine mammals to climate-induced habitat change. Ecological Applications 18, S97-S125.

McLaren I.A. 1961. Methods for determining the numbers and availability of ringed seals in the eastern Canadian Arctic. Arctic 14, 162-175.

Pollock K.H., Marsh H.D., Lawler I.R. \& Alldredge M.W. 2006. Estimating animal abundance in heterogeneous environments: an application to aerial surveys for dugongs. Journal of Wildlife Management 70, 225-262.

Richard P.R., Hobbs R.C., Laake J.L., Heide-Jørgensen M.P., Asseli N. \& Cleator H. In press. Baffin Bay narwhal population distribution and numbers: aerial surveys in the Canadian High Arctic, 2002-2004. Arctic.

Serreze M.C. \& Francis J.A. 2006. The Arctic amplification debate. Climate Change 76, 241-264, doi: 10.1007/ s10584-005-9017-y.

Stern H.L. \& Heide-Jørgensen M.P. 2003. Variability of sea ice in Baffin Bay and Davis Strait. Polar Research 22, 11-18.

Thomas L., Laake J.L., Strindberg S., Marques F.F.C., Buckland S.T., Borchers D.L., Anderson D.R., Burnham K.P., Hedley S.L., Pollard J.H., Bishop J.R.B. \& Marques T.A. 2006. Distance 5.0. St. Andrews: Research Unit for Wildlife Population Assessment, University of St. Andrews. 